\title{
Animal Rights and Use of Animals in Biomedical Research
}

\section{Zoheb Rafique}

Lecturer

Department of Biochemistry,

Liaquat University of Medical \& Health Sciences (LUMHS),

Jamshoro, Pakistan

Email: dr zohaib@hotmail.com

Abstract: Experiments on animals have always been considered as necessary for scientific research, both fundamental and applied. In addition to scientific suitability criteria, this practice also must be justified from a moral point of view. This concern arises from the demand of our civilization that a certain moral value be recognized to animals. In this paper it is discussed in detail that how animals should be handled while doing research and what are animal rights and their uses in biomedical research.

Key words: animal Rights, biomedical Research

Introduction: Questions about the way animals are treated in research became more prominent in recent decades in a period which has been particularly favorable for freedom of research and science which promotes technological and scientific progress. At the start of the twenty-first century, it is obvious to the scientific community, as well as to the public, that science often raises some ethical questions. In the areas of animal-based research, teaching and testing, these include questions about the justification for studies involving distress and pain, which are detrimental to animal welfare. Determining the behavioral and social needs of an animal and deciding how these needs can best be met are further concerns, arising from the of behavioral biology and animal welfare science, which should inform the debate about the use of animals. The research into and testing of almost every major medical treatment has involved the use of animals at different occasions. However, for as long as animals have been used to better understand the functioning of the animal and human body, the thoughtful researchers and general public have also concerned themselves with issues arising from that use. In particular, the question of distress and pain has been the main focus of concern ${ }^{1}$. In this paper, I will discuss the animal rights and the use of animals in biomedical research. This paper will focus on the way the animals should be handled ethically during the biomedical research.

Discussion: Animal use as research subjects in medical investigations is widely condemned on two grounds. First, because it wrongly imposes on sentient creatures much avoidable sufferings. Second, because it wrongly violates the rights of animals. Neither of the above argument is sound. The first relies on a mistaken calculation of consequences; the second relies on a mistaken understanding of rights. It does not follows from this, however, that we are morally free to do anything we please to animals certainly not. A right, properly understood, is a claim that one party may exercise against another. The target against whom such a claim is registered can be a single person, a community, a group, or all humankind. Immanuel Kant was influential in his emphasis on universal human possession of uniquely moral will. Humans confront choices which are purely moral. Human beings are morally autonomous and self legislative. Animals lack this capacity for free moral judgment. They are not capable of responding or exercising to 
moral claims ${ }^{2}$. This importance of a humane care and treatment of animals used for research and teaching is increasing and constitutes a responsibility we all share. Each time research and teaching involves animal participation, it is very essential that the welfare of those animals is properly considered. It places upon the researchers and investigators a primary responsibility to observe the professional, ethical and legal principles involved ${ }^{3}$. It is very important that the work involving animals within the research project proceeds in a way that is ethically acceptable. Ethically acceptable research procedures must follow legislation for animal-based research: respecting the minimum requirements for animal housing, use of anesthesia, treatment procedures etc. For a researcher concerned with ethical aspects of his activity, it is important to strive to follow the general intentions of the law, such as attempting to find non-animal alternatives, and trying to minimize the number of animals used etc. It is essential that the intended experiments involving animals be subject to an ethics discussion beforehand. It is very important to demonstrate the potential benefit of the experiments and that reasonable measures have been taken to protect the welfare of the experimental animals ${ }^{4}$. Every year more than 20 million animals are used in the biomedical research projects and from these 20 million more than 90 percent of them being rats, mice, and other rodents. From the other animal species, approximately 65,000 dogs, 23,000 cats, and 55,000 primates were used for research purposes only in the United States between the period October 1, 2003 and September 30, 2004 according to U.S. Department of Agriculture ${ }^{5}$. While not all biomedical researchers involve the use of animals, animals are essential in many areas. The short life span of research animals allows researchers and scientists to study them throughout the entire life cycle, and even through several generations-within a very short period of time. Using laboratory animals in scientific studies allows researchers precise control over the animal's environment (temperature, light, ventilation) to ensure that animals are healthy and thus keep experimental variables to a minimum. Healthy, well cared-for, adequately housed animals are necessary to produce accurate research results. Following examples are animal contributions to research. Cats for studies of AIDS, eye and ear disorders, and the nervous system, armadillos for vaccine for leprosy, dogs for coronary bypass surgery; artificial heart valve insertion; pacemaker implantation; hip and other joint replacement surgery, chinchillas for studies on middle ear infections and hearing loss, ferrets for viral diseases such as influenza, fish for studies of vision, liver cancer, bacterial diseases, temperature regulation, and skin tumors, Guinea pigs for nutritional studies such as vitamin C deficiency, Lobsters for study of motor coordination diseases such as syphilis and Parkinson's disease, mice for studies of cancer, aging, AIDS, immunology, and genetics; embryo transfer techniques in humans and domestic and endangered animal species, nonhuman primates for treatments for polio and Rh disease; studies of HIV and AIDS, cancer, heart disease, neurological disorders, and infectious diseases such as malaria, Opossums for studies of the central nervous system, immune system, and bacterial endocarditis, pigeons for study of coronary heart disease, pigs for burn treatments; development of the CAT Scan; human heart valve replacements, Rabbits for corneal transplant; drugs that lower blood cholesterol and help stop the development of hardening of the arteries; rats for studies to find treatment for paralysis caused by nerve damage; product safety tests; causes of some cancer; effects of nutrition on aging; understanding tissue rejection following transplant surgery, sheep for development of the arteriovenous shunt and testing of a device that assists lung functions in infants soon after birth, woodchucks for liver cancer and hepatitis B and Slugs for studies of the short-and long-term memory ${ }^{6}$. The rationale for using animal models in biomedical research is scientific and animal models are likely to remain necessary until science develops other alternative models and systems that are equally robust and sound. The use of animal models in science, and biomedical research, is accepted by majority of lay people and scientists alike as being necessary to the advancement of useful knowledge that brings about relief from suffering. Some outside of biomedical scientific community, however, have a clear understanding of why these animal 
models are important. This is very unfortunate. Man and animals are symbiotic in many ways and not just on an ideological level. Arguments regarding whether biomedical science can advance without using animals are frequently mooted and makes as much sense as questioning if clinical trials are necessary before any new medical therapies are allowed to be widely used in the general population. While the use of animals has decreased in the last two decades, advances in genetic research and the demands of research to counter bio-terrorism are expected to reverse this trend and lead to an increase in use of animals. At the heart of it, all is the health and safety of humans ${ }^{7}$. Since Islam is predominant culture and religion in our country and according to Islamic rules, life is divine present to all creatures, then, no one have authority to interfere animal's life without their permission. Animals are part of this truth of life; hence, we can use them only with respect for their status and dignity that has been created. Animals should always be used in an ethical manner, because they are creatures which have pain and distress senses. According to Islam, humans should know their limitations and positions in nature; therefore we are not allowed to use animals in the way we desire. Our religious rules obligate us to avoid causing distress and suffering to animals, therefore, we should try to protect animal wellbeing in research, teaching and testing ${ }^{8}$. Although the main principles of "Western" bioethics (autonomy, beneficence, non-maleficence and justice) are acceptable according to Islam, their interpretation can differ. For example, there is a limit on autonomy, because sometimes the interest of the society is preferred to individual rights. In Muslim countries, in various discussions on medical ethics, we have a tendency to look towards religion. Islam is believed to be able to fully restore the harmony between science and religion. The principles of bioethics and solutions to ethical problems are derived from the Islamic legal rulings. The main principles of Islamic ethics are the respect for human dignity, eternity of life and life after death, benevolence to fellow human beings, altruism, seeking perfection and eternal salvation. There is wide overlap between Islamic bioethics, law and the Islamic rulings, so that the religious principles such as the eternity of life could be very important in the ethical decision making in Islamic setting ${ }^{9}$.The strong position implies that animals possess the right to respectful treatments, and this entails that they not be treated only as a means to some other end. They end in themselves, and this intrinsic worth makes it wrong to use animals as subject in research. The weak position on the animal rights would maintain that even for humans the right to life is not absolute, that rights frequently conflict, and that in circumstances where human rights conflict with animal rights, a judgment will be necessary. Therefore, an animal's right creates a duty, which to some degree restricts our behavior. Since a person's life is more important than any animal, the use of animals for medical purpose is morally acceptable. This position can be compressed to a claim that animals have some rights, without duties, and may justifiably be sacrificed for a variety of human purposes ${ }^{10}$.

Conclusion: Although in this article I have focused on animal use in research, other areas also raise ethical concerns about animal rights and animal welfare. These include the use of animals as companions, in zoos, in agriculture, education, for entertainment or sport, and the treatment of wildlife and endangered species ${ }^{11}$. We should encourage others to become informed about the vital issue of using animals in biomedical research. As we begin to understand the facts more fully, we will agree that the judicious use of animals in research offers the greatest hope of improving the lives of both animals and humans.

\section{References:}

1. Gauthier C, Griffin G. Using animals in research, testing and teaching. Rev Sci tech. off. int. Epiz. 2005; 24(2):735745 . 
2. Cohen C. Use of Animals in Biomedical Research. New Engl J Med 1985; 315(14):865-870.

3. Vieuille C, Aubert A.. The human-animal relationship in higher scientific education and its ethical implications. Animal Bioethics: Principles and Teaching Methods. Binnenwerk bioethics. 2005; 173-182.

4. Olsson A, Sandoe P. Guidelines for ethical conduct with animals-comparative genomics of man and pig.

5. U.S. Department of Agriculture: www.aphis.usda.gov/ac

6. Use of Animals in Biomedical Research. Understanding the Issues. American Association for laboratory Animal Science. www.aalas.org. [Retrieved]

7. Chow P. The Rationale for the use of Animal Models in Biomedical Research 2007; Chapter 1.1:2-10

8. Mobasher et al. Proposing a National Ethical Framework for Animal Research in Iran. Iranian J Publ Health 2008; $37(1): 39-46$.

9. Zahedi F, Larijani B. National bioethical legislation and guidelines for Biomedical research in the Islamic Republic of Iran. Bulletin World Health Organ 2008; 86:630-634.

10. Lei RP. Is the use of animal organs for transplants morally acceptable? Debates over the use of animals in xenotransplantation. Turkiye Klinikleri. J Med Ethics. 2004; 12:242-247.

11. Bishop LJ, Nolen AL. Animals in Research and Education: Ethical Issues. National Reference Center for Bioethics Literature. The Joseph and Rose Kennedy Institute of Ethics. Reprint issued March 2001; 1-19.

Conflict of interest: Author declares no conflict of interest. 